\title{
The efficacy and safety of knotless barbed sutures in total joint arthroplasty: a meta-analysis of randomized-controlled trials
}

\author{
Yanhong Han ${ }^{1,3} \cdot$ Weiyi Yang ${ }^{2}$. Jianke Pan ${ }^{2,3}$. Lingfeng Zeng ${ }^{2,3}$. Guihong Liang ${ }^{2,3}$. Jiongtong Lin ${ }^{1,3} \cdot$ Minghui Luo $^{2}$. \\ Da Guo ${ }^{2} \cdot$ Jun Liu ${ }^{2,3}$
}

Received: 22 January 2018 / Published online: 16 June 2018

(c) The Author(s) 2018

\begin{abstract}
Background The knotless barbed sutures (KBS) are an innovative type of suture that can accelerate the placement of sutures and eliminate knot tying. Whether the KBS are safe and efficient in total joint arthroplasty (TJA) remains controversial. Therefore, we conducted a meta-analysis to evaluate its efficacy and safety.

Methods Randomized-controlled trials (RCTs) were identified from the PubMed, Embase, and Cochrane Library databases up to October 2017. The Cochrane risk of bias tool was used to assess methodological quality. The statistical analysis was performed with RevMan 5.3.5 software.

Results A total of five RCTs (600 participants) were included in our meta-analysis. The results showed that KBS reduced wound suture time (MD $-4.51,95 \% \mathrm{CI}-5.37$ to $-3.66, P<0.00001)$ and the wound suture cost $(\mathrm{MD}-282.63,95 \% \mathrm{CI}$ -445.32 to $-119.95, P<0.00001$ ), and did not significantly increase the rate of complications (OR $0.77,95 \%$ CI $0.42-1.39$, $P=0.13$ ) or intraoperative events (OR $0.86,95 \%$ CI $0.04-17.28, P=0.92)$. There were no significant differences in ROM at postoperative 6 weeks and 3 months (MD $-0.74,95 \% \mathrm{CI}-4.19$ to $2.71, P=0.67$; $\mathrm{MD}-0.30,95 \% \mathrm{CI}-2.62$ to 2.02 , $P=0.80$; respectively).

Conclusion Our findings suggest that KBS are a safe and effective method for TJA. Given the possible biases, adequately powered and better designed studies with longer follow-up are required to reach a firmer conclusion.
\end{abstract}

Keywords Knotless barbed sutures $\cdot$ Total joint arthroplasties $\cdot$ Knotted traditional sutures $\cdot$ Randomized control trials, meta-analysis

\section{Introduction}

As the population ages and medical technology have improved, the rate of total joint arthroplasties (TJA) has increased considerably over the past decades. Total hip

Yanhong Han, Weiyi Yang, and Jianke Pan have contributed equally to this work.

Jun Liu

liujun3040@126.com

1 Second School of Clinical Medicine, Guangzhou University of Chinese Medicine, Guangzhou 510405, China

2 Department of Orthopedics, Second Affiliated Hospital, Guangzhou University of Chinese Medicine, No. 111 Dade Road, Guangzhou 510120, Guangdong, China

3 Bone and Joint Research Team of Degeneration and Injury, Guangdong Provincial Academy of Chinese Medical Sciences, Guangzhou 510120, China arthroplasty (THA) and total knee arthroplasty (TKA) are well-known popular surgical procedures for the treatment of degenerative disorders and traumatic diseases. This rapid growth in the number of surgeries has also coincided with innovations in surgical procedures that have improved postoperative function and minimized complications. However, improper soft-tissue handling remains a risk factor for complications after TJA. Secure wound closure is key to preventing infection, facilitating immediate rehabilitation, and improving the efficiency of TJA [1]. Therefore, sutures have received increasing attention in terms of innovation, as certain features can enable faster suturing and greater convenience in TJA. In addition, their quality is crucial for minimizing wound complications and withstanding force across the incision during the early postoperative joint motion [2].

The knotless barbed sutures (KBS) were first described by R.A. Mckenzie in 1967 [3], and the bidirectional barbed suture was first introduced in 2007 [1]. At present, KBS 
are used in several surgical specialties [4]. KBS has been demonstrated to provide better soft-tissue repair and shorter closure times than knotted traditional sutures (KTS) in urology, obstetrics, and plastic surgery [5-7]. However, whether KBS are efficient and safe in TJA remains controversial. Several studies have found that KBS offers several advantages, including shorter closure time, elimination of the need for knot tying and handling of multiple sutures, improved tissue distribution, and the use of less suture material [8-10]. Moreover, its postoperative clinical outcomes are similar to those of KTS [11-14]. Despite these potential advantages, barbed sutures are not commonly used in TJA. This might be due to their higher cost and uncertain clinical benefits. The previous research on the use of KBS in TJA is limited and has yielded conflicting results [15]. Some studies showed that barbed sutures were associated with more wound complications, whereas others found that they reduced closure time and costs $[2,11]$. Campbell et al. found that KBS use was associated with a higher rate of infections requiring antibiotics than wound closure with KTS [15]. Furthermore, work of Smith et al. suggests that KBS are associated with a greater frequency and severity of wound-related complications [16].

Some meta-analyses have recently been conducted regarding the use of KBS in TJA. However, the outcomes of previous meta-analyses are unclear, and no studies have comprehensively examined the benefits of KBS. Consequently, no reliable evidence regarding which of the two suture methods (KBS or KTS) leads to better outcomes and lower rates of complications in TJA. Therefore, we performed a meta-analysis of published clinical research to assess the efficiency and safety of KBS in patients undergoing THA and TKA.

\section{Methods}

\section{Search strategy}

A comprehensive search of the PubMed, EMBASE, and Cochrane Library databases up to October 2017 was performed. The search terms included "knotless", "barbed", "arthroplasty, replacement, knee", "total knee arthroplasty", "total knee replacement", "total knee prosthesis", "arthroplasty, replacement, hip", "total hip arthroplasty", "total hip replacement", and "total hip prosthesis". The references of the identified studies were manually searched.

\section{Selection criteria}

The inclusion criteria were as follows: (1) randomized-controlled trials (RCTs); (2) patients treated with primary total knee or hip arthroplasty; (3) knotless barbed sutures compared with knotted traditional suture; (4) data available for at least one of the key outcomes, including closure time, complications, closure cost, intraoperative events, Knee Society Score (KSS), or range of motion (ROM).

The exclusion criteria were as follows: (1) duplicate articles; (2) case reports, cohort studies, reviews, editorials, letters, and animal experimental studies; (3) data that could not be extracted.

\section{Data extraction}

Two reviewers independently extracted the following data from the included studies: authors' names, date of publication, sample size, patients' age and gender, surgery type, closure time, complications, closure cost, follow-up periods, KSS, ROM, suture material, total closure time in the operating room, and intraoperative events. In the event of missing data, we attempted to contact the corresponding authors for details.

\section{Quality assessment}

The methodological quality of the included studies was independently evaluated by two reviewers using the Cochrane Collaboration's tool for assessing the risk of bias. These domains were selection bias (random sequence generation and allocation concealment), performance bias (blinding of participants and personnel), detection bias (blinding of outcome assessments), attrition bias (incomplete outcome data), reporting bias (selective reporting) and other bias (other sources of bias). Any disagreements were resolved by discussion or were arbitrated by the corresponding author.

\section{Statistical analysis}

The meta-analysis was performed using Review Manager 5.3.5 (Cochrane Collaboration, Oxford, UK). Odds ratios (OR) and mean differences (MD) were used to pool dichotomous and continuous data, respectively. The pooled estimates regarding outcomes expressed as either dichotomous or continuous variables were calculated using the random-effects model (postoperative complications were assessed using the fixed-effects model). Heterogeneity was assessed using the Cochrane Q test and the I-square statistic. A sensitivity analysis was performed to identify the source of the heterogeneity. For all analyses, $P<0.05$ was considered statistically significant.

\section{Results}

\section{Study selection}

A total of 29 records were identified via database and manual searches. After a thorough screening of titles and 
abstracts, seven records were excluded. The remaining 22 articles were assessed by full-text reviews. Finally, five studies met the inclusion criteria and were included in the metaanalysis (Fig. 1).

\section{Characteristics of the included studies}

The characteristics of the included studies are presented in Table 1. Two studies involved TKA and THA $[11,16]$, and the remaining studies only involved TKA. The data set consisted of 600 participants, including 656 TKAs and 41 THAs. Among these, 345 participants' wounds were closed with KBS and 352 with KTS. The gender ratio, average age, and types of surgery were also noted. In each study, the demographic characteristics of the two groups were similar.

For TKA and THA, details regarding the exact type of suture used, the relevant cost of suture material, and closure time are reported in Table 2. For surgeries involving both KBS and KTS, the placement and type of stitches varied. For surgeries using the KTS method, subcuticular tissue was closed with a running suture in three studies $[1,2,16]$, while others used the interrupted suture technique. In the KBS group, the arthrotomy was closed with a running KBS in all studies.

\section{Risk of bias}

The assessment of risk of bias is shown in Fig. 2. Random sequence generation was mentioned in all the included studies. Three of the studies detailed the methods of randomization $[2,11,16]$. Three studies described adequate allocation concealment $[2,11,16]$. All the studies mentioned the blinding methods: only one performed double-blinding of surgeons and assessors, and the others performed blinding
Fig. 1 Flow diagram of identified, included, and excluded studies

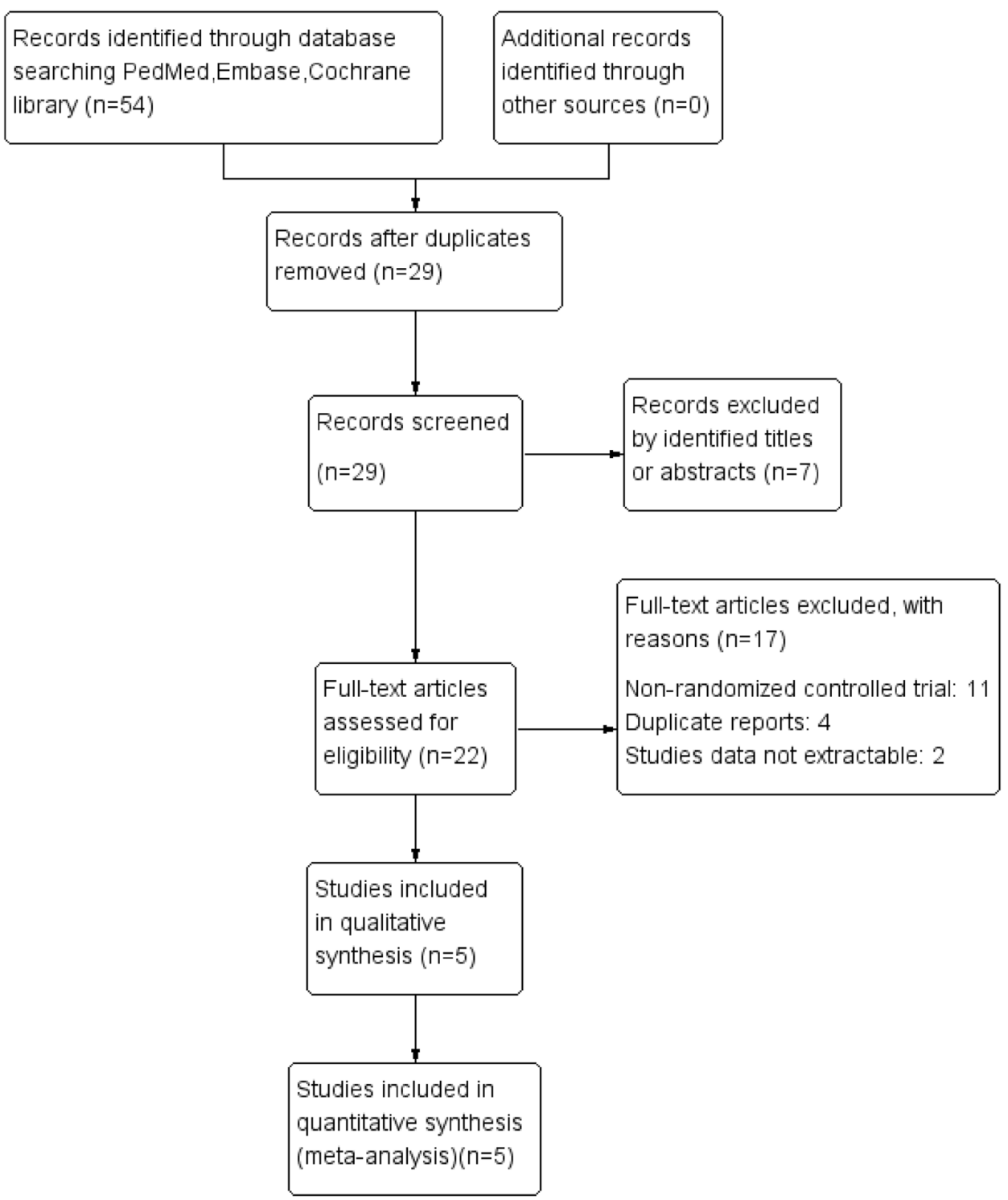




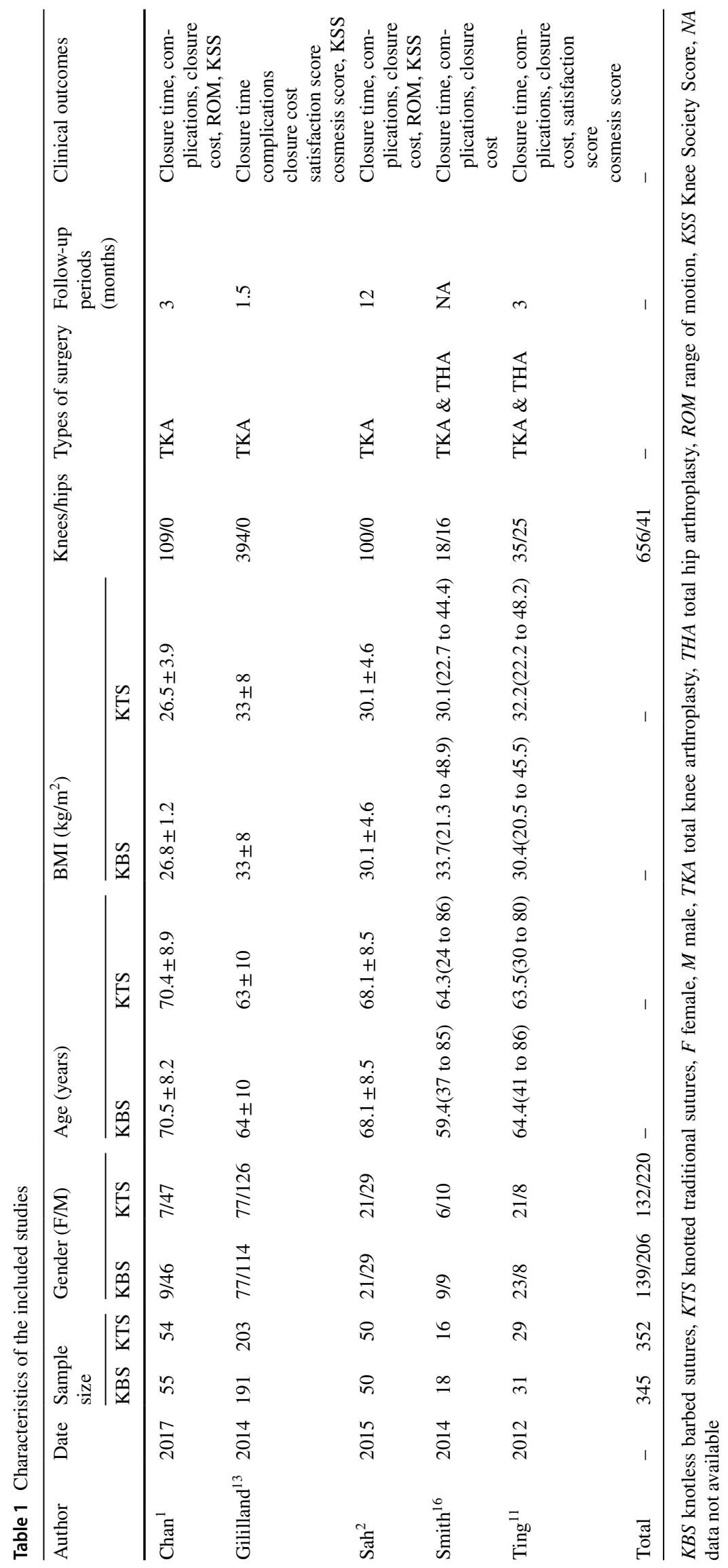


Table 2 Suture type and cost of suture materials in the KBS and KTS groups

\begin{tabular}{|c|c|c|c|c|c|c|c|c|c|}
\hline \multirow[t]{2}{*}{ Author } & \multirow[t]{2}{*}{ Date } & \multicolumn{2}{|c|}{ Suture materials compared } & \multicolumn{2}{|c|}{$\begin{array}{l}\text { Average suture } \\
\text { material costs }\end{array}$} & \multicolumn{2}{|c|}{$\begin{array}{l}\text { Total closure time in the } \\
\text { operating room (minutes) }\end{array}$} & \multicolumn{2}{|c|}{ Total suture cost $($ mean $\pm \mathrm{SD})$} \\
\hline & & KBS & KTS & KBS & KTS & KBS & KTS & KBS & KTS \\
\hline Chan $^{1}$ & 2017 & $\begin{array}{l}\text { Arthrotomy } \\
\text { closure: } \\
\text { 1-Stratafix } \\
\text { Subcutane- } \\
\text { ous closure: } \\
\text { 0-Stratafix } \\
\text { Skin closure: } \\
\text { surgical } \\
\text { staples }\end{array}$ & $\begin{array}{l}\text { Arthrotomy clo- } \\
\text { sure: 1-Vicryl } \\
\text { Subcutaneous } \\
\text { closure: } 2 / 0 \\
\text { Vicryl } \\
\text { Skin closure: } \\
\text { surgical } \\
\text { staples }\end{array}$ & $\$ 61.90$ & $\$ 14.50$ & $10.52 \pm 1.78$ & $14.53 \pm 3.16$ & $\$ 313.75 \pm \$ 42.61$ & $\$ 362.35 \pm \$ 75.65$ \\
\hline Gililland $^{13}$ & 2014 & $\begin{array}{l}\text { Arthrotomy clo- } \\
\text { sure: knotless } \\
\text { \#2 Quill SRS } \\
\text { PDO } \\
\text { Subdermal clo- } \\
\text { sure: knotless } \\
\text { 0 Quill SRS } \\
\text { Monoderm } \\
\text { Skin closure: } \\
\text { staples }\end{array}$ & $\begin{array}{l}\text { Arthrotomy } \\
\text { closure: } \\
\text { interrupted \#1 } \\
\text { Ethibond } \\
\text { Subdermal } \\
\text { closure: } 2-0 \\
\text { Monocryl } \\
\text { Skin closure: } \\
\text { staples }\end{array}$ & $\$ 24$ & $\$ 2$ & $9.8 \pm 4.2$ & $14.4 \pm 3.98$ & $\$ 324 \pm \$ 118$ & $\$ 419 \pm \$ 116$ \\
\hline $\mathrm{Sah}^{2}$ & 2015 & $\begin{array}{l}\text { Retinaculum } \\
\text { closure: } 2 \\
\text { Quill } \\
\text { Deep-interme- } \\
\text { diate layer } \\
\text { closure: } 2-0 \\
\text { Vicryl } \\
\text { Subcutaneous } \\
\text { closure: } 2-0^{\text {Monoderm }}{ }^{\mathrm{TM}} \\
\text { Subcuticular } \\
\text { closure: } 2-0 \\
\text { Monoderm }\end{array}$ & $\begin{array}{l}\text { Retinaculum } \\
\text { closure: } 1 \text { Vic- } \\
\text { ryl }{ }^{\mathrm{TM}} \text { pop-off } \\
\text { sutures } \\
\text { Deep-interme- } \\
\text { diate layer } \\
\text { closure: } 2-0 \\
\text { Vicryl } \\
\text { Subcutaneous } \\
\text { closure: } 2-0 \\
\text { Monocryl } \\
\text { Subcuticular } \\
\text { closure: } 3-0 \\
\text { Monocryl }\end{array}$ & $\$ 82$ & $\$ 32$ & $11.4 \pm 2.2$ & $16.1 \pm 2.1$ & $\$ 307.6 \pm \$ 134.4$ & $\$ 804.8 \pm \$ 100.8$ \\
\hline Smith $^{16}$ & 2014 & $\begin{array}{l}\text { Fascia closure: } \\
\text { \#2 Quill } \\
\text { Fat closure: \#1 } \\
\text { Quill } \\
\text { Subcutaneous } \\
\text { closure: \#0 } \\
\text { Quill } \\
\text { Subcuticular } \\
\text { closure: 2-0 } \\
\text { Quill Mono- } \\
\text { derm }\end{array}$ & $\begin{array}{l}\text { Fascia closure: } \\
\text { \#1 Ethibond } \\
\text { Fat closure: } \\
\text { 0-Vicryl } \\
\text { Subcutaneous } \\
\text { closure: } 2.0 \\
\text { Vicryl } \\
\text { Subcuticular } \\
\text { closure: } 3-0 \\
\text { Monocryl }\end{array}$ & $\$ 106.33$ & $\$ 14.40$ & $16.78 \pm 3.28$ & $26.50 \pm 6.83$ & $\$ 1213.8 \pm \$ 216.48$ & $\$ 1763.4 \pm \$ 450.78$ \\
\hline Ting $^{11}$ & 2012 & $\begin{array}{l}\text { Deep fascia clo- } \\
\text { sure: 2-polydi- } \\
\text { oxanone } \\
\text { Subcutane- } \\
\text { ous closure: } \\
\text { 0-polydiox- } \\
\text { anone } \\
\text { Subdermal } \\
\text { closure: } 2-0 \\
\text { monoderm } \\
\text { Skin closure: } \\
\text { skin staples } \\
\text { and adhesive }\end{array}$ & $\begin{array}{l}\text { Deep fascia clo- } \\
\text { sure: } 1 \text {-Vicryl } \\
\text { Subcutane- } \\
\text { ous closure: } \\
\text { 0-Vicryl } \\
\text { Subdermal } \\
\text { closure: } 2-0 \\
\text { monofilament } \\
\text { Skin closure: } \\
\text { skin staples } \\
\text { and adhesive }\end{array}$ & $\$ 52.84$ & $\$ 9.43$ & $9.2 \pm 1.88$ & $12.7 \pm 3.08$ & $\$ 1000.44 \pm \$ 316.73$ & $\$ 1317.53 \pm \$ 193.13$ \\
\hline
\end{tabular}

$K B S$ knotless barbed sutures, $K T S$ knotted traditional sutures, $S D$ standard deviation 
of the study surgeons or assessors. None of the studies had a high risk of incomplete outcome data due to a lack of details regarding some adverse events. In addition, reporting bias and other bias were not described in any of the included studies.

\section{Wound closure time}

All five studies reported the wound closure time [1, 2, 11, 13, 16]; subsequently, the data from these studies were pooled. The pooled results showed that KBS significantly reduced the wound closure time ( $\mathrm{MD}-4.51,95 \% \mathrm{CI}-5.37$ to $-3.66, P<0.00001$; Fig. 3$)$, with moderate heterogeneity $\left(P=0.02, I^{2}=64 \%\right)$.

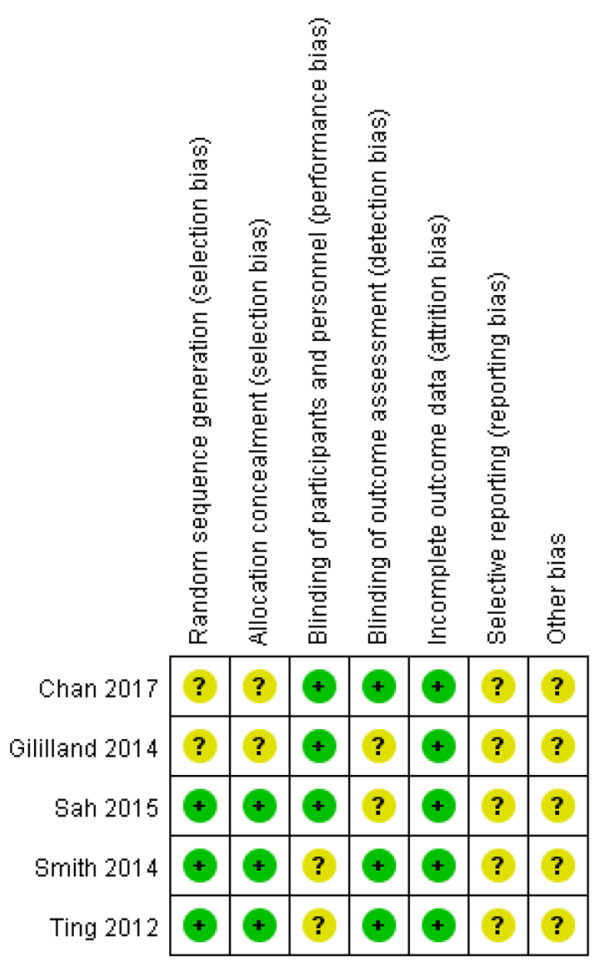

Fig. 2 Summary of risk of bias for the included RCTs

\section{Complications}

All five studies reported the complications [1, 2, 11, 13, 16]; subsequently, the data from these studies were pooled. Patients in both groups experienced similar rates of complications (OR 0.77, 95\% CI 0.42-1.39, $P=0.38, I^{2}=43 \%$, $P=0.13$; Fig. 4). Full details regarding complications are summarized in Table 3. There were no differences between the two groups in the rates of stitch abscess, dehiscence, cellulitis, peri-incisional erythema, or pulmonary embolism.

\section{Knee range of motion}

Two studies reported knee ROM at 6 weeks and 3 months after surgery [1, 2]. Therefore, we performed subgroup meta-analyses to compare the knee ROM based on the date. Full details for knee ROM are summarized in Table 3. There were no significant differences between the two groups at postoperative 6 weeks and 3 months (MD - 0.74, 95\% CI -4.19 to $2.71, P=0.67, I^{2}=0 \%, P=0.50 ; \mathrm{MD}-0.30,95 \%$ CI -2.62 to $2.02, P=0.80, I^{2}=73 \%, P=0.05$; respectively; Fig. 5).

\section{Knee Society Score}

Three studies reported the KSS after surgery [1, 2, 13]. Therefore, we performed subgroup meta-analyses to compare the KSS based on the date. Full details for the KSS are summarized in Table 3. There were no significant heterogeneities among the subgroups $\left(P=0.37, I^{2}=0 \% ; P=0.35\right.$, $I^{2}=0 \%$; respectively, Fig. 6). At postoperative 3 months, the KBS group obtained a higher KSS. However, there were no significant differences between the two groups at postoperative 6 weeks and 1 year.

\section{Wound closure cost}

All five studies reported the wound closure cost [1, 2, 11, 13, 16]; subsequently, the data from these studies were pooled. The cost differences in terms of closure time in the operating

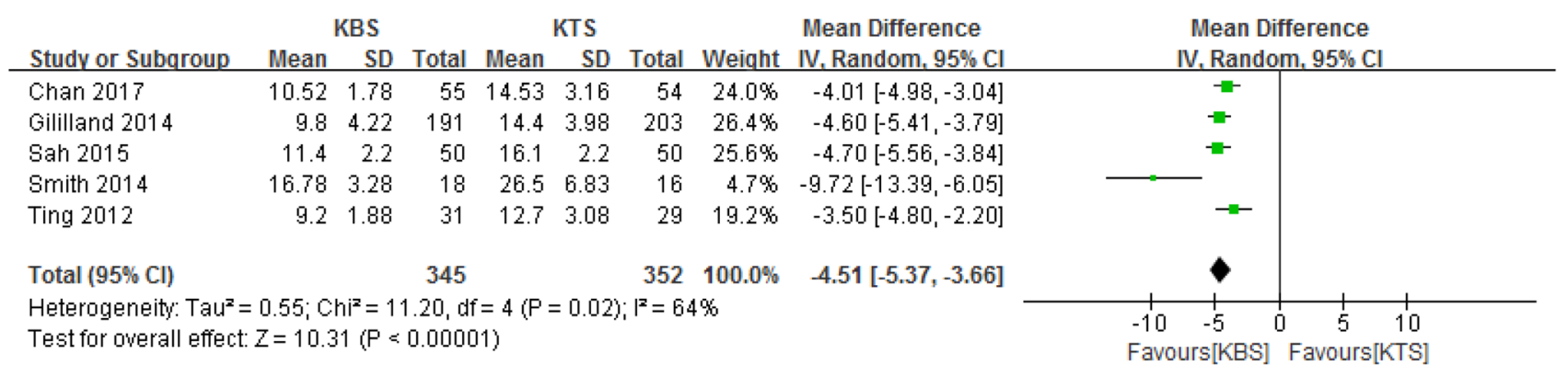

Fig. 3 Forest plot and meta-analysis of wound closure time 


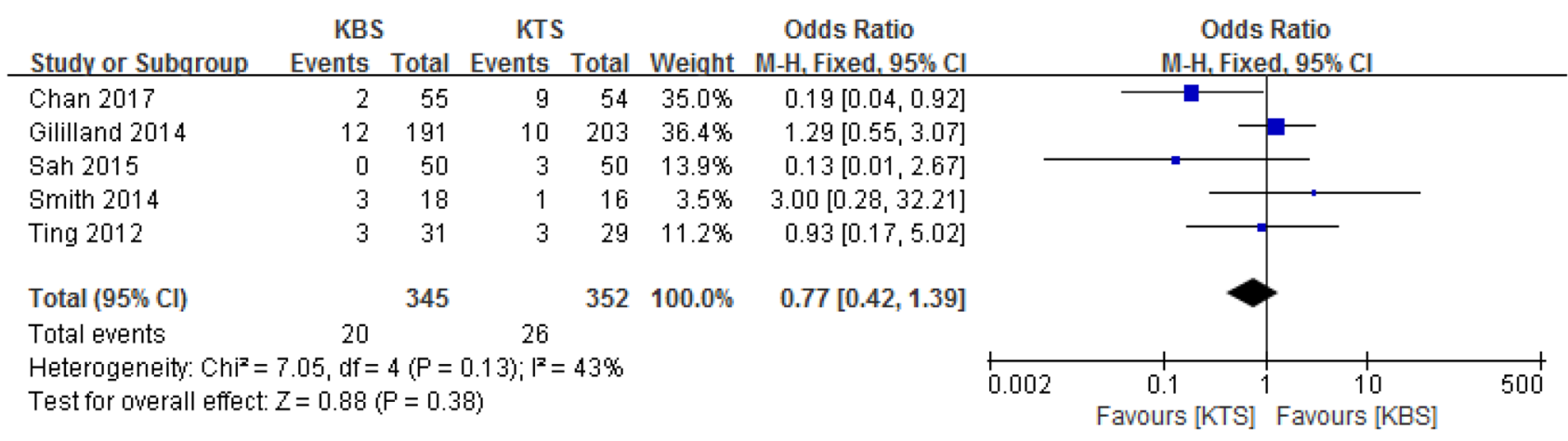

Fig. 4 Forest plot and meta-analysis of complications

Table 3 Pooled outcomes of all the subgroups

\begin{tabular}{|c|c|c|c|c|c|c|}
\hline Outcomes & $\begin{array}{l}\text { No. of } \\
\text { studies }\end{array}$ & $\begin{array}{l}\text { No. of cases } \\
\text { KBS/KTS }\end{array}$ & $\mathrm{SMD} / \mathrm{MD} / \mathrm{OR}$ & $95 \% \mathrm{CI}$ & Heterogeneity & $P$ value of effect size \\
\hline \multicolumn{7}{|l|}{ Wound suture time } \\
\hline Arthrotomy & 2 & $73 / 70$ & -1.62 & {$[-2.00,1.24]$} & $P=0.45 ; I^{2}=0 \%$ & $Z=8.34(\mathrm{P}<0.00001)$ \\
\hline Subcutaneous & 2 & $73 / 70$ & -1.17 & {$[-2.07,0.28]$} & $P=0.04 ; I^{2}=76 \%$ & $Z=2.57(P=0.01)$ \\
\hline \multicolumn{7}{|l|}{ Wound complications } \\
\hline Stitch abscess & 3 & $296 / 307$ & 0.53 & {$[0.20,1.37]$} & $P=0.16 ; I^{2}=45 \%$ & $Z=1.32(P=0.19)$ \\
\hline Wound dehiscence & 2 & $105 / 104$ & 0.31 & {$[0.03,3.13]$} & NA & $Z=0.99(P=0.32)$ \\
\hline Cellulitis & 3 & $264 / 273$ & 1.31 & {$[0.48,3.58]$} & $P=0.35 ; I^{2}=4 \%$ & $Z=0.53(P=0.60)$ \\
\hline Peri-incisional erythema & 1 & $31 / 29$ & 0.60 & {$[0.09,3.86]$} & NA & $Z=0.54(P=0.59)$ \\
\hline Pulmonary embolism & 1 & $191 / 203$ & 3.20 & {$[0.13,79.15]$} & NA & $Z=0.71(P=0.48)$ \\
\hline \multicolumn{7}{|l|}{ Knee range of motion } \\
\hline$\leq 6$ weeks & 2 & $105 / 104$ & -0.74 & {$[-4.19,2.71]$} & $P=0.50 ; I^{2}=0 \%$ & $Z=0.42(P=0.67)$ \\
\hline$\leq 3$ months & 2 & $105 / 104$ & -0.30 & {$[-2.62,2.02]$} & $P=0.05 ; I^{2}=75 \%$ & $Z=0.26(P=0.80)$ \\
\hline \multicolumn{7}{|l|}{ Knee society score } \\
\hline$\leq 6$ weeks & 2 & $246 / 257$ & -0.22 & {$[-3.10,2.66]$} & $P=0.37 ; I^{2}=0 \%$ & $Z=0.15(P=0.88)$ \\
\hline$\leq 3$ months & 2 & $105 / 104$ & -2.04 & {$[-3.92,0.15]$} & $P=0.35 ; I^{2}=0 \%$ & $Z=2.12(P=0.03)$ \\
\hline 1 year & 1 & $50 / 50$ & -0.5 & {$[-3.03,2.03]$} & NA & $Z=0.39(P=0.70)$ \\
\hline \multicolumn{7}{|l|}{ Intraoperative events } \\
\hline Suture breakages & 2 & $241 / 253$ & 1.99 & {$[0.01,401.87]$} & $P=0.010 ; I^{2}=85 \%$ & $Z=0.25(P=0.80)$ \\
\hline Needle stick injuries & 1 & $191 / 203$ & 0.21 & {$[0.02,1.80]$} & NA & $Z=1.43(P=0.15)$ \\
\hline
\end{tabular}

KBS knotless barbed sutures, KTS knotted traditional sutures, $S M D$ standardized mean difference, $M D$ mean difference, $O R$ odds ratio, $N A$ not applicable

room and materials between the two groups are summarized in Table 2. Analysis of the pooled cost data showed that KBS was associated with 282.63 USD lower costs than KTS (MD - 282.63, 95\% CI -445.32 .00 to $-119.95, P=0.0007$, $I^{2}=99 \%, P<0.00001$, Fig. 7).

\section{Intraoperative events}

Data for intraoperative events were only available in two studies $[2,13]$, and the results showed high heterogeneity $\left(P=0.05, I^{2}=73 \%\right)$. Therefore, we performed subgroup meta-analyses to compare the different intraoperative events
(Table 3). The pooled results showed that there were no significant differences between the two groups in terms of intraoperative events (OR $0.86,95 \%$ CI $0.04-17.28, P=0.92$; Fig. 8).

\section{Result of the subgroup analysis}

Table 3 shows the results of the subgroup analysis. KBS significantly reduced the arthrotomy and subcutaneous wound closure times. No significant difference was observed in the risk of different complications. There were no significant differences between the two groups in postoperative knee 


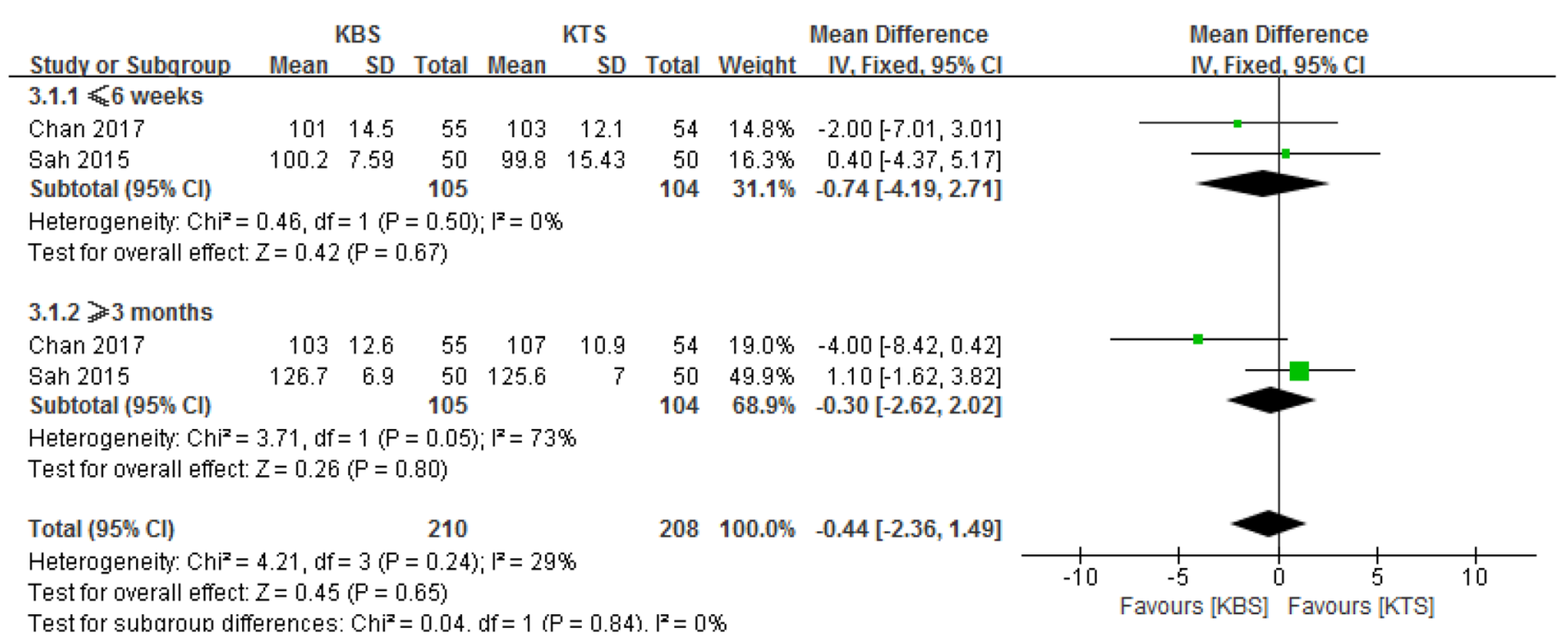

Fig. 5 Forest plot and meta-analysis of knee range of motion

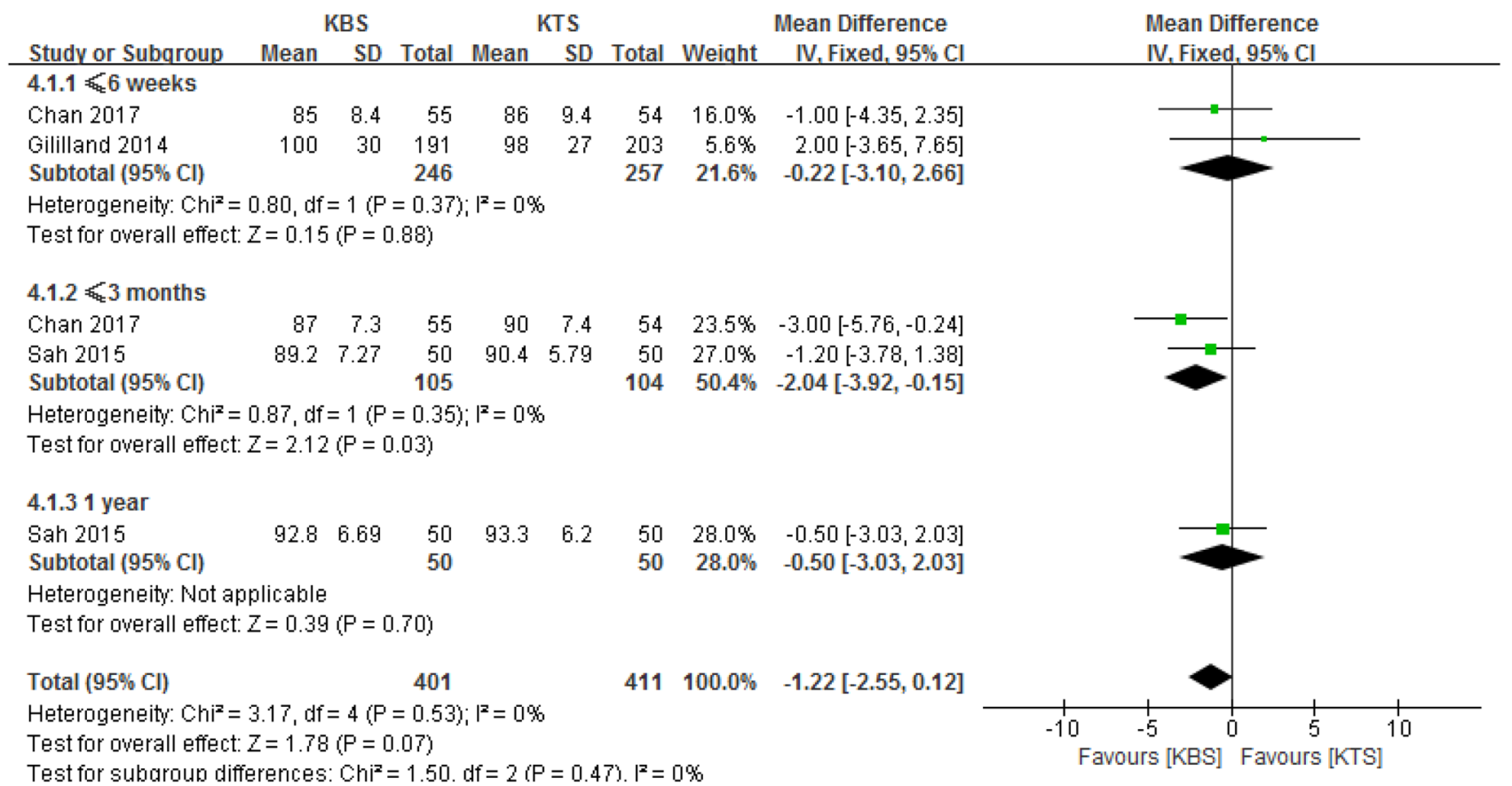

Fig. 6 Forest plot and meta-analysis of Knee Society Score

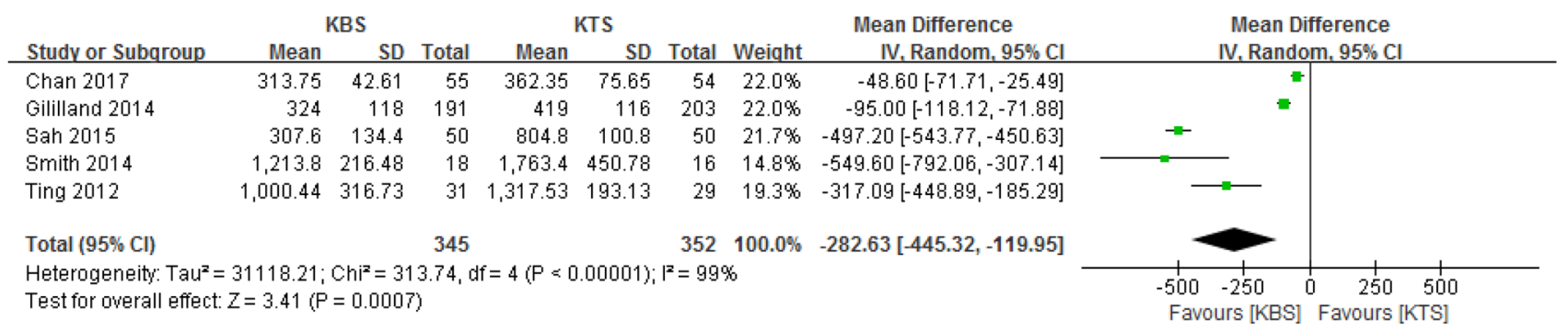

Fig. 7 Forest plot and meta-analysis of cost 
ROM and KSS. However, the KBS obtained a higher KSS at postoperative 3 months. The incidence of intraoperative events did not differ significantly between the two groups.

\section{Discussion}

To our knowledge, the risk that KBS use will increase the incidence of potential complications in TJA remains controversial. Our review incorporated 5 studies and 600 participants who were treated with primary TKA or THA. The purpose of our meta-analysis was to determine whether KBS could reduce wound closure times, costs, and potential complications. In this analysis of studies, we found that (1) KBS were not clearly associated with intraoperative events, postoperative functional recovery, or complications, and (2) KBS could reduce wound closure times and closure costs.

As reported in a previous study, KBS were able to reduce wound suturing time in our study [17-20]. Eickmann et al. found that KBS saved approximately $11.5 \mathrm{~min}$ in TKA compared with KTS [14]. Furthermore, in Mansour's study of spinal fusion, KBS reduced the wound suture time by $40 \%$. Theoretically, KBS are self-anchored and does not require a knot, thus allowing faster closure [12]. However, we performed a subgroup analysis, because the wound suture time showed high heterogeneity. The subgroup analysis showed that the suture times for different layers were better in the KBS group than in the KTS group despite the heterogeneity of the subcutaneous layer sutures. Because the surgical procedure differs for the treatment of joint incisions and shallow skin closures, a significant heterogeneity of wound suturing times is hard to prevent.

According to the previous studies, the use of KBS may lead to more postoperative complications compared with KTS [15, 21]. In general, the junction can cause uneven pressure on the soft tissue, leading to ischaemia, and large adsorption junctions may lead to local tissue inflammation and scar formation, which are potential risk factors for infection. Shermak found that KBS increased the risk of complications of arm wound healing, suggesting that the increase in surface area caused by barbs and continuous stitching results in the spread of inflammation along the length of the closure
[22]. However, we observed no difference in the overall incidence of these complications between TJA surgeries with KBS and KTS, consistent with the findings of Zhang [20]. Taking into account the clinical differences among the different complications, we conducted a subgroup analysis; the results showed that the rates of different complications did not differ significantly between the KBS and KTS groups. This may be because KBS provides more uniform tissue tension, which reduces the risk of ischaemia, and a lack of nodules, which reduces the potential for local inflammatory response and extruded suture/sterile abscess, thereby reducing the risk of wound complications [13, 23].

Moreover, there were no differences in the incidence of intraoperative events between the KBS and KTS groups. The traditional stitching method requires interruptions for knotting, which increase the risk of suture breakages and needle stick injuries. In contrast, KBS allows continuous stitching and avoid the traditional knot, thereby reducing the rate of intraoperative events. There may be considerable heterogeneity in the intraoperative events associated with wound suturing due to the different surgical procedures used for KBS. In addition, in Chan's studies, there were significantly more positive leak tests in the KTS group. A study of simulated tonic arthritis of the body found that, compared with KTS, the use of KBS closure decreased the leakage rate by $74 \%$ [10]. Due to the uniform distribution of the barbs over the entire suture, the breakage or loosening of a single suture ring does not easily cause the entire suture to fail. This is important for ensuring the watertight closure of joint incision wounds [10].

The quality of wound closure is critical to the high tension resistance of knee surgery wounds, especially for rapid recovery regimens. Our study found no significant difference in postoperative ROM values between patients who received KBS and those who received KTS in the early ( $<6$ weeks) and midterm $(<3$ months) postoperative periods. This result is consistent with the previous reports that there is no significant difference between KBS and KTS in terms of the average degree of extension and flexion and the KSS score [12-14]. In the midterm ( $<3$ months), the patients who received KBS had a higher KSS than those who received KTS, and this difference was clinically

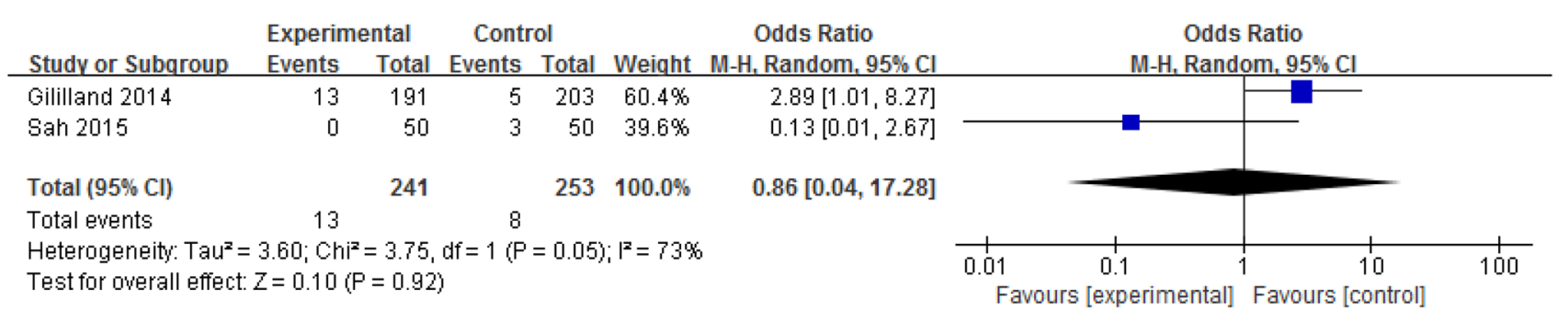

Fig. 8 Forest plot and meta-analysis of intraoperative events 
unimportant. However, whether there is a difference in the long-term efficacy of KBS and KTS requires RCTs with long-term follow-up to determine the effect of suture type on functional recovery.

Our analysis found that KBS significantly reduced the cost of TJA surgery. Similarly, Zhang found that KBS could reduce wound closure time by $3.56 \mathrm{~min}$ and reduce costs by $\$ 290.72$ compared with KTS [20]. These savings are comparable to those reported in this study; however, the cost savings are dependent on the operating costs in each region. The average cost of surgery in 100 US hospitals was $\$ 62$ per minute (range \$22-133 per minute) [24]. The estimated operating room costs are based on the average cost of the professionals and resources required for these operations. It is noteworthy that although KBS materials are more expensive than KTS materials, the shorter operating time leads to lower overall costs. Another implication of the time-saving nature of KBS is the reduced cost associated with its use. When cost-effectiveness is calculated, we should consider overall resource utilization. Currently, no studies have truly addressed the issue of cost in a way that is relevant to most institutions. In addition to cost savings, less time in the operating room reduces exposure to anaesthesia, which is safer for patients and helps to control healthcare costs. These potential benefits were not considered in the cost analysis.

To the best of our knowledge, this meta-analysis of the validity and safety of KBS and KTS includes all randomizedcontrolled trials. However, it has the following restrictions. Mainly because of the different levels of stitching, a variety of suture methods were used, and the stitching technique was not uniform; consequently, a significant heterogeneity in the wound suture time and total cost was inevitable. In addition, the included studies were less focused on evaluating hip function post-TKA. In all studies, the follow-up time was relatively short, which prevented an assessment of long-term efficacy, especially in terms of postoperative functional examinations. Finally, the limited number of studies, the small number of samples, the different protocols used, and the different backgrounds of the participants may weaken our analysis. Therefore, more high-quality research is needed in the future to determine the effectiveness and safety of KBS in TJA.

Acknowledgements Conceived and designed the experiments: Jun Liu and Yanhong Han; performed the experiments: Weiyi Yang, Jianke Pan, and Lingfeng Zeng; analysed the data: Guihong Liang, Minghui Luo, and Da Guo; wrote the paper: Yanhong Han and Jianke Pan. We thank American Journal Experts for their linguistic assistance during the preparation of this manuscript.

Funding This study was supported by National Ministry of Industry and the State Health Planning Commission "orthopedic surgery robot application center" construction projects (No. 2017MHDOSR1008), Project of Guangdong Provincial Department of Finance (No. [2014]157, No. [2018]8), Science and Technology Research
Project of Guangdong Provincial Hospital of Chinese Medicine (No. YKYN2015MS15).

\section{Compliance with ethical standards}

Conflict of interest We declare that we have no conflict of interest.

Ethical approval This article does not contain any studies with human participants or animals performed by any of the authors.

Open Access This article is distributed under the terms of the Creative Commons Attribution 4.0 International License (http://creativeco mmons.org/licenses/by/4.0/), which permits unrestricted use, distribution, and reproduction in any medium, provided you give appropriate credit to the original author(s) and the source, provide a link to the Creative Commons license, and indicate if changes were made.

\section{References}

1. Chan V, Chan PK, Chiu KY, Yan CH, Ng FY (2017) Does barbed suture lower cost and improve outcome in total knee arthroplasty? A randomized controlled trial. J Arthroplast 32(5):1474-1477. https://doi.org/10.1016/j.arth.2016.12.015

2. Sah AP (2015) Is there an advantage to knotless barbed suture in TKA wound closure? A randomized trial in simultaneous bilateral TKAs. Clin Orthop Relat Res 473(6):2019-2027. https://doi. org/10.1007/s11999-015-4157-5

3. McKenzie AR (1967) An experimental multiple barbed suture for the long flexor tendons of the palm and fingers. Preliminary report. J Bone Joint Surg Br 49(3):440-447

4. Maheshwari AV, Naziri Q, Wong A, Burko I, Mont MA, Rasquinha VJ (2015) Barbed sutures in total knee arthroplasty: are these safe, efficacious, and cost-effective? J Knee Surg 28(2):151156. https://doi.org/10.1055/s-0034-1373741

5. Paul MD (2013) Barbed sutures in aesthetic plastic surgery: evolution of thought and process. Aesthet Surg J 33(3 Suppl):17S-31S. https://doi.org/10.1177/1090820X13499343

6. Wright RC, Gillis CT, Yacoubian SV, Raven RR, Falkinstein Y, Yacoubian SV (2012) Extensor mechanism repair failure with use of bidirectional barbed suture in total knee arthroplasty. J Arthroplast 27(7):1411-1413. https://doi.org/10.1016/j.arth.2011.08.013

7. Villa MT, White LE, Alam M, Yoo SS, Walton RL (2008) Barbed sutures: a review of the literature. Plast Reconstr Surg 121(3):102e-108e. https://doi.org/10.1097/01.prs.0000299452 .24743 .65

8. Vakil JJ, O'Reilly MP, Sutter EG, Mears SC, Belkoff SM, Khanuja HS (2011) Knee arthrotomy repair with a continuous barbed suture: a biomechanical study. J Arthroplast 26(5):710-713. https ://doi.org/10.1016/j.arth.2010.07.003

9. Zaruby J, Gingras K, Taylor J, Maul D (2011) An in vivo comparison of barbed suture devices and conventional monofilament sutures for cosmetic skin closure: biomechanical wound strength and histology. Aesthet Surg J 31(2):232-240. https://doi. org/10.1177/1090820X10395010

10. Nett M, Avelar R, Sheehan M, Cushner F (2011) Water-tight knee arthrotomy closure: comparison of a novel single bidirectional barbed self-retaining running suture versus conventional interrupted sutures. J Knee Surg 24(1):55-59

11. Ting NT, Moric MM, Della VC, Levine BR (2012) Use of knotless suture for closure of total hip and knee arthroplasties: a 
prospective, randomized clinical trial. J Arthroplast 27(10):17831788. https://doi.org/10.1016/j.arth.2012.05.022

12. Gililland JM, Anderson LA, Sun G, Erickson JA, Peters CL (2012) Perioperative closure-related complication rates and cost analysis of barbed suture for closure in TKA. Clin Orthop Relat Res 470(1):125-129. https://doi.org/10.1007/s11999-011-2104-7

13. Gililland JM, Anderson LA, Barney JK, Ross HL, Pelt CE, Peters CL (2014) Barbed versus standard sutures for closure in total knee arthroplasty: a multicenter prospective randomized trial. J Arthroplast 29(9 Suppl):135-138. https://doi.org/10.1016/j. arth.2014.01.041

14. Eickmann T, Quane E (2010) Total knee arthroplasty closure with barbed sutures. J Knee Surg 23(3):163-167

15. Campbell AL, Patrick DJ, Liabaud B, Geller JA (2014) Superficial wound closure complications with barbed sutures following knee arthroplasty. J Arthroplasty 29(5):966-969. https://doi. org/10.1016/j.arth.2013.09.045

16. Smith EL, DiSegna ST, Shukla PY, Matzkin EG (2014) Barbed versus traditional sutures: closure time, cost, and wound related outcomes in total joint arthroplasty. J Arthroplast 29(2):283-287. https://doi.org/10.1016/j.arth.2013.05.031

17. Mansour A, Ballard R, Garg S, Baulesh D, Erickson M (2013) The use of barbed sutures during scoliosis fusion wound closure: a quality improvement analysis. J Pediatr Orthop 33(8):786-790. https://doi.org/10.1097/BPO.0b013e3182a11eee
18. Stephens S, Politi J, Taylor BC (2011) Evaluation of primary total knee arthroplasty incision closure with the use of continuous bidirectional barbed suture. Surg Technol Int 21:199-203

19. Levine BR, Ting N, Della VC (2011) Use of a barbed suture in the closure of hip and knee arthroplasty wounds. Orthopedics 34(9):e473-e475. https://doi.org/10.3928/01477447-20110714-35

20. Zhang W, Xue D, Yin H et al. (2016) Barbed versus traditional sutures for wound closure in knee arthroplasty: a systematic review and meta-analysis. Sci Rep 6:19764. https://doi. org/10.1038/srep19764

21. Lin Y, Lai S, Huang J, Du L (2016) The efficacy and safety of knotless barbed sutures in the surgical field: a systematic review and meta-analysis of randomized controlled trials. Sci Rep 6:23425. https://doi.org/10.1038/srep23425

22. Shermak MA, Mallalieu J, Chang D (2010) Barbed suture impact on wound closure in body contouring surgery. Plast Reconstr Surg 126(5):1735-1741. https://doi.org/10.1097/PRS.0b013e3181ef8fa 3

23. Murtha AP, Kaplan AL, Paglia MJ, Mills BB, Feldstein ML, Ruff GL (2006) Evaluation of a novel technique for wound closure using a barbed suture. Plast Reconstr Surg 117(6):1769-1780. https://doi.org/10.1097/01.prs.0000209971.08264.b0

24. Macario A (2010) What does one minute of operating room time cost? J Clin Anesth 22(4):233-236. https://doi.org/10.1016/j.jclin ane.2010.02.003 